\title{
Влияние регулятора роста Лостор на урожайность чеснока
}

\section{А.В. Поляков, Т.В. Алексеева, С.В. Логинов, П.А. Стороженко}

Установлено, что двукратная обработка вегетирующих растений чеснока озимого регулятором роста Лостор в концентрации 0,1 г/л способствует повышению урожайности на 15,9\% по сравнению с контролем и на 8,7\% по сравнению с Энергией М, а также повышению массы луковиц на 18,4\% по сравнению с контролем и на 12,0\% по сравнению с эталоном. Предпосадочная обработка зубков чеснока ярового с последующей двукратной обработкой вегетирующих растений способствует повышению урожайности луковиц на 28,9\% по сравнению с контролем и на 13,8\% по сравнению с эталоном, а также повышению массы луковиц на 27,8\% по сравнению с контролем и на 14,3\% по сравнению с эталоном.

Ключевые слова: чеснок озимый, чеснок яровой, растение, регулятор роста.

$\Pi$ отребность рынка страны в чесноке составляет приблизительно 430 тыс. т. ежегодно, при этом АПК России производит оКОло 260 тыс. т. Расширение посевных площадей этой культуры сдерживает нехватка качественного посадочного материала [1, 2]. Несмотря на то, что в Реестре селекционных достижений РФ на 2018 год включено 77 сортов чеснока озимого и 14 сортов чеснока ярового, практически невозможно купить качественный посевной материал большинства этих сортов.

Использование посадочного материала ввозимого из-за границы, осложнено тем, что чеснок не переносит смены почвенно-климатических условий.

Целью нашего исследования было исследовать влияние регулятора роста нового поколения Лостор на урожайность чеснока озимого и ярового.

Исследования проведены в отделе биотехнологии и инновационных проектов ВНИИО - филиала ФГБНУ ФНЦО (Московская область, Раменский район) в 2016-2018 годах.

В работе использовали регулятор роста Лостор (производитель ООО «Флора Си»). В качестве эталона использовали препарат Энергия М того же производителя. Энергия М - широко распространенный регулятор роста, зарегистрированный в 2008 году. Препарат хорошо себя зарекомендовал при использовании на подсолнечнике, корнеплодах, капусте и других овощных культурах [4].

Опыты проведены на чесноке озимом сорта Гладиатор [5] и чесноке яровом сортообразца Тверской 3. Схема опыта предполагала проведение предпосадочной обработки зубков в течение 30 мин. и последующую двукратную обработку вегетирующих растений чеснока ярового и двукратную обработку вегетирующих растений чеснока озимого в начале интенсивного роста листьев и при появлении соцветий препаратом в концентрации 0,01, 0,05 и 0,1 мл/л. Доза препарата 30 мл/ $\mathrm{M}^{2}$. В качестве эталона использовали препарат Энергия М в концентрации 0,1 г/л. В качестве контроля использовали обработку растений водой.

Исследования, проведенные на чесноке озимом, показали, что применение препарата Лостор в период вегетации растений было эффективно во всех вариантах. Однако применение его в концентрации 0,1 г/л было наиболее эффективным и способствовало увеличению урожайности луковиц на $15,9 \%$ по сравнению с контролем. В этом варианте обработки урожайность луковиц была на 8,7\% выше по сравнению с эталоном - обработкой препаратом Энергия М. Кроме того, обработка растений Лостором в этой концентрации способствовала увеличению массы луковицы на 18,4\% по сравнению с контролем и на $12,0 \%$ по сравнению с эталоном, а также увеличению воздушно-сухой массы растений на $20,0 \%$ по сравнению с контролем и на $12,0 \%$ по сравнению с эталоном (табл.). Существенных различий по отрастанию зубков и высоте растений между вариантами не отмечено. Различия не наблюдались и по длине вегетационного периода.
В этом опыте не отмечено поражения растений фитопатогенными бактериями и вредителями. В вариантах обработки растений препаратом луковиц, пораженных фитопатогенными грибами, тоже не было обнаружено, однако в контроле доля луковиц, пораженных фузариозом, составляла $1,1 \%$.

Обработка зубков чеснока ярового перед посадкой Лостором и последующая двукратная обработка в период вегетации привела к существенному повышению урожайности луковиц во всех вариантах обработки. Однако применение препарата в концентрации 0,1 г/л также было наиболее эффективым и способствовало повышению урожайности луковиц на 28,9\% по сравнению с контролем и на $13,8 \%$ по сравнению с эталоном. Применение Лостора в этой концентрации привело к увеличению массы луковиц на 27,8\% по сравнению с контролем и на $14,3 \%$ по сравнению с эталоном, а также повышению воздушно-сухой массы растений на 29,8\% по сравнению с контролем и на $14,4 \%$ по сравнению с эталоном (табл.).

В конце вегетации в контроле растения чеснока ярового в средней степени были поражены ржавчиной. Пораженных растений в вариантах опыта не отмечено. Различия по дружности отрастания, длине вегетационного периода, поражению фитопатогенными бактериями и вредителями не наблюдались.

Выводы. Установлено, что двукратная обработка вегетирующих растений чеснока озимого препаратом Лостор, а также предпосадочная обработка зубков чеснока ярового с последующей двукратной обработкой вегетирующих растений этим препаратом в концентрации 0,1 г/л способствует:

- повышению урожайности луковиц: у чеснока озимого - на $15,9 \%$ по сравнению с контролем и на 8,7\% по сравнению с Энергией М; у чеснока ярового - на $28,9 \%$ по сравнению с контролем и на $13,8 \%$ по сравнению с эталоном.

- повышению массы луковиц: у чес 
Хозяйственно ценные признаки чеснока озимого и ярового при обработке росторегулирующими препаратами, 2016-2018 годы

\begin{tabular}{|c|c|c|c|c|c|c|c|c|c|}
\hline \multirow{3}{*}{$\begin{array}{l}\text { Вариант } \\
\text { опыта }\end{array}$} & \multirow{3}{*}{$\begin{array}{c}\text { Концентрация } \\
\text { вещества, } \\
\text { Г(мл)/л }\end{array}$} & \multirow{2}{*}{\multicolumn{2}{|c|}{ Высота растений }} & \multicolumn{4}{|c|}{ Macca } & \multirow{2}{*}{\multicolumn{2}{|c|}{ Урожайность }} \\
\hline & & & & \multicolumn{2}{|c|}{ растения } & \multicolumn{2}{|c|}{ луковицы } & & \\
\hline & & $\mathrm{CM}$ & $\%$ & г & $\%$ & $\Gamma$ & $\%$ & $\mathrm{~K} \Gamma / \mathrm{M}^{2}$ & $\%$ \\
\hline \multicolumn{10}{|c|}{ Чеснок озимый } \\
\hline $\begin{array}{c}\text { Вода (конт- } \\
\text { роль) }\end{array}$ & 0 & 101 & 100,0 & 38,0 & 100,0 & 34,2 & 100,0 & 1,51 & 100,0 \\
\hline $\begin{array}{c}\text { Энергия M } \\
\text { (эталон) }\end{array}$ & $0,1+0,1$ & 106 & 105,0 & 40,7 & 107,1 & 36,2 & 105,8 & 1,61 & 106,6 \\
\hline \multirow{3}{*}{ Лостор М1 } & $0,1+0,1$ & 109 & 107,9 & 45,6 & $120,0 /{ }^{*} 112,0$ & 40,5 & $118,4 /{ }^{*} 112,0$ & 1,75 & $115,9 /{ }^{*} 108,7$ \\
\hline & $0,05+0,05$ & 107 & 105,9 & 41,4 & $108,9 /{ }^{*} 101,7$ & 37,0 & $108,2 / * 102,2$ & 1,68 & $111,3 /{ }^{*} 104,3$ \\
\hline & $0,01+0,01$ & 103 & 102,0 & 41,0 & $107,9 /{ }^{*} 100.7$ & 36,5 & $106,7 /{ }^{*} 100,8$ & 1,66 & $109,9 /{ }^{*} 103,1$ \\
\hline \multicolumn{10}{|c|}{ Чеснок яровой } \\
\hline $\begin{array}{c}\text { Вода } \\
\text { (контроль) }\end{array}$ & 0 & 48,8 & 100,0 & 23,5 & 100,0 & 21,2 & 100,0 & 0,83 & 100,0 \\
\hline $\begin{array}{c}\text { Энергия M } \\
\text { (эталон) }\end{array}$ & $0,1+0,1$ & 49,6 & 101,6 & 26,6 & 113,0 & 23,7 & 111,8 & 0,94 & 113,3 \\
\hline \multirow{3}{*}{$\begin{array}{l}\text { Лостор И + } \\
\text { Лостор М1 }\end{array}$} & $0,1+0,1+0,1$ & 51,3 & 105,1 & 30,5 & $129,8 /{ }^{*} 114,4$ & 27,1 & $127,8 / * 114,3$ & 1,07 & $128,9 / * 113,8$ \\
\hline & $0,05+0,05+0,5$ & 50,0 & 102,5 & 27,7 & $117,9 /{ }^{*} 104,1$ & 25,0 & $117,9 / * 105.5$ & 0,97 & $116,9 / * 103,2$ \\
\hline & $0,01+0,01+0,01$ & 49,3 & 101,0 & 2,63 & $111,9 / * 98,9$ & 23,3 & $109,9 /{ }^{\star} 98,3$ & 0,92 & $110,8 /{ }^{\star} 97,9$ \\
\hline
\end{tabular}

нока озимого - на 18,4\% по сравнению с контролем и на 12,0\% по сравнению с эталоном; у чеснока ярового на 27,8\% по сравнению с контролем и на 14,3\% по сравнению с эталоном.

\section{Библиографический список}

1.Государственный реестр селекционных достижений. Т.1. Сорта растений. М., 2018. С. 268-269.

2.Поляков А.В., Разин А.Ф. Алексеева Т.В. Эффективность выращивания посадочного материала чеснока озимого в Нечерноземной зоне Российской Федерации // Аграрная Россия. 2018. №11. С. 45-48. 3.Петриченко В.Н., Логинов С.В. Применяйте кремнийорганические регуляторы роста // Картофель и овощи. 2010. №3. С. 14-15.

4.Петриченко В.Н., Логинов С.В., Туркина О.С. Влияние регуляторов роста и микроудобрений на обменные процессы в столовых корнеплодах // Аграрная Россия. 2014. №8. С. 10-12.

5.Поляков А.В. Гладиатор - новый сорт чеснока озимого // Картофель и овощи. 2013. № 9. С. 19-21.

\section{Об авторах}

\section{Поляков Алексей Васильевич,}

доктор биол. наук, профессор, г.н.с. отдела биотехнологии и инновационных проектов, Всероссийский научно - исследовательский институт овощеводства - филиал ФГБНУ «Федеральный научный центр овощеводства»; профессор кафедры ботаники и прикладной биологии Московского государственного областного университета.

Тел. +7 (906) 707-69-47.

E-mail:vita100plus@yandex.ru

Алексеева Татьяна Вячеславовна, м.н.с. отдела биотехнологии и инновационных проектов, ВНИИО - филиал ФГБНУ ФНЦО; старший преподаватель кафедры ботаники и прикладной биологии Московского государс- твенного областного университета. Тел. + 7 (915) 460-26-05.

E-mail: matilda8691@gmail.com

Логинов Сергей Витальевич, доктор хим. наук, в.н.с., Государственный Научный Центр Российской

Федерации, Акционерное Общество «Государственный научно-исследовательский институт химии и технологии элементоорганических соединений». Тел. : +7 (965) 180-07-63.

E-mail: florasilik@yandex.ru

Стороженко Павел Аркадьевич, академик РАН, доктор хим. наук, Государственный Научный Центр Российской Федерации, ген. директор АО «Государственный научно-исследовательский институт химии и технологии элементоорганических соединений».

Тел. : +7 (495) 673-72-01.

E-mail: info@eos.su

The effect of the growth regulator Lostor on the yield of garlic

A.V. Polykov, DSc, professor, chief

research fellow of biotehnoligical and innovation project department, All-Russian

Research Institute of Vegetable Growing

- branch of FSBSI Federal Research

Center of Vegetable Growing; professor

of department botany and applied biology

Moscow State Region University

Phone: +7 (906) 707-69-47.

E-mail: vita100plus@yandex.ru

T.V. Alekseeva, junior research fellow of department of biotechnological and innovation project department, ARRIVG branch of FSBSI Federal Research Center of Vegetable Growing; senior lecturer of department botany and applied biology Moscow State Region University. Phone: +7 (915) 460-26-05.

E-mail: matilda8691@gmail.com

S.V. Loginov, DSc, leading researcher, The State Scientific Center of the Russian federation State Research Institute for Chemistry and Technology of Organoelement Compounds.

Phone: +7(965) 180-07-63.

E-mail: florasilik@yandex.ru

P.A. Storozhenko, academician of

RAS, DSc, The State Scientific Center of the Russian federation State Research Institute for Chemistry and Technology of

Organoelement Compounds.

Phone: +7(495) 673-72-01.

E-mail:info@eos.su

Summary. It was found that double treatment of winter garlic vegetating plants with the growth regulator Lostor at a concentration of $0.1 \mathrm{~g} / \mathrm{I}$ resulted an increase in yield by $15.9 \%$ compared to the control and by $8.7 \%$ compared to the Energia $M$, as well as an increase in the mass of bulbs by $18.4 \% \mathrm{com}$ pared to the control and by $12.0 \% \mathrm{com}$ pared to the standard. Pre-planting treatment of spring garlic cloves followed by double treatment of vegetative plants resulted an increase in the yield of bulbs by $28.9 \%$ compared to the control and $13.8 \% \mathrm{com}$ pared to the standard, as well as an increase in the weight of bulbs by $27.8 \%$ compared to the control and $14.3 \%$ compared to the standard.

Keywords: garlic winter, garlic summer, plants, growth regulators. 